\title{
Video interview in new media
}

\author{
L. G. Antonova ${ }^{1}$, A. I. Makhalova ${ }^{1}$
}

1P. G. Demidov Yaroslavl State University, 14 Sovetskaya str., Yaroslavl 150003, Russian Federation

DOI: $10.18255 / 2412-6519-2020-1-92-99$

Research Article

Full text in Russian

The article is devoted to the analysis of video interviews in new media in the context of the complex, integrated concept of «hypergenre». The material of video interviews published in YouTube, attempts to characterize genres, a complex combination of which is modern video interviews in new media. Special parameters of the hypergenre should be characterized on the Internet platform, which provides additional tools in genre design, including hyperlinks, video podcasts, special technologies for illustrating and confirming factuality, specific video metaphors and video quotes. The authors believe that, unlike print or television media, this hypergenre on the Internet platform acts simultaneously as an informational, analytical, and as an artistic and journalistic, which provides an opportunity to «consider» the features of related genres included in the integrative genre complex: conversations, chronicle notes, surveys, commentary, investigative journalism and some other media genres. Another feature of modern video interviews, explaining the special role of non-verbal signs, implicitly transmitting semantic signals in the context of video interviews, which include gestures, facial expressions, pro-semitic speaker, his personal image signs and tone of speech. As a result of the study of the new model of video interviews, the authors of the article offer a generalized media toolkit of modern hypergenre education and explain the demand and popularity of such a model in the mass media.

Keywords: hypergenre; video interviews; new media; YouTube channel; author and addressee factor; language embodiment

INFORMATION ABOUT THE AUTHORS

$$
\begin{array}{r|l}
\begin{array}{r}
\text { Antonova L. G. } \\
\text { (correspondence author) }
\end{array} & \begin{array}{l}
\text { E-mail: antonova_lubov@mail.ru } \\
\text { Doctor of Sciences in Pedagogy, Professor }
\end{array} \\
\text { Makhalova A. I. } & \begin{array}{l}
\text { E-mail: amberos7@gmail.com } \\
\text { Master student }
\end{array}
\end{array}
$$

For citation: Antonova L. G., Makhalova A. I. Video interview in new media // Social'nye i gumanitarnye znanija. 2020. Vol. 6, No 1. P. 92-99. (in Russ.) 


\title{
Жанровые особенности видеоинтервью в новых медиа
}

\author{
Л. Г. Антонова ${ }^{1}$, А. И. Махалова ${ }^{1}$
}

1Ярославский государственный университет им. П. Г. Демидова, ул. Советская, 14, Ярославль, 150003, Российская Федерация

Статья посвящена анализу видеоинтервью в новых медиа в контексте сложного, интегрированного понятия «гипержанр». На материале видеоинтервью, опубликованных на YouTube, предпринимается попытка охарактеризовать жанры, сложная комбинация которых составляет современное видеоинтервью в новых медиа. Особые параметры гипержанра следует характеризовать именно на интернет-платформе, которая обеспечивает дополнительный инструментарий в жанровом оформлении, включая гиперссылки, видеоподкасты, особые технологии для иллюстрирования и подтверждения фактологичности, специфические видеометафоры и видеоцитаты. Авторы считают, что, в отличие от печатных или телевизионных СМИ, данный гипержанр на интернет-платформе выступает одновременно и как информационный, аналитический, и как художественно-публицистический, что дает возможность "рассмотреть» черты смежных жанров, включенных в интегративный жанровый комплекс: беседы, хроникальной заметки, опроса, комментария, журналистского расследования и некоторых других медийных жанров. Внутрижанровое исследование видеоинтервью в новых медиа проводится с учетом вербального и невербального оформления жанровой модели, где прежде всего отмечается активный поиск автором материала индивидуального стиля. Выявляется и другая особенность современного видеоинтервью, объясняющая роль невербальных знаков, имплицитно передающих смысловые сигналы в контексте видеоинтервью, к числу которых относятся жесты, мимика, проксемика говорящего, его личные имиджевые знаки и тональность речи. В результате исследования новой модели видеоинтервью авторы статьи предлагают обобщенный медиаинструментарий современного гипержанрового образования и объясняют востребованность и популярность подобной модели в масс-медиа.

Ключевые слова: гипержанр; видеоинтервью; новые медиа; YouTube-канал; фактор автора и адресата; языковое воплощение

\section{ИНФОРМАЦИЯ ОБ АВТОРАХ}

Антонова Любовь Геннадьевна (автор для корреспонденции)

Махалова Алеся Игоревна
E-mail: antonova_lubov@mail.ru

Доктор педагогических наук, профессор, зав. кафедрой теории и практики коммуникации

Email: amberos7@gmail.com

Магистрант факультета филологии и коммуникации

Для цитирования: Антонова Л. Г., Махалова А. И. Жанровые особенности видеоинтервью в новых медиа // Социальные и гуманитарные знания. 2020. Том 6, № 1. С. 92-99.

(C) Антонова Л. Г., Махалова А. И., 2020

Статья открытого доступа под лицензией СC BY-NC-ND (http://creativecommons.org/licenses/by-nc-nd/4.0/) 
Одной из главных задач в современном жанроведении является создание собственной системы терминов, определение основных понятий, многие из которых появились сравнительно недавно - в последние два-три десятилетия. Подвижность системы жанров проявляется в образовании новых жанров, в смешении жанров, в трансформации существующих жанров [1]. К числу таких достаточно новых ключевых понятий, нуждающихся в определении и глубоком исследовании, относится гипержанр.

В российском жанроведении одним из первых ученых, употребивших термин «гипержанр», является К. Ф. Седов. Исследователь, научные интересы которого были связаны в основном с проблемами психолингвистических и этнокультурных особенностей жанра, предложил следующее определение: «Гипержанры - это макрообразования, т. е. речевые формы, которые сопровождают социально-коммуникативные ситуации, объединяющие в своём составе несколько жанров» [Цит. по 2, с. 149].

В словаре-справочнике «Эффективное речевое общение» под редакцией А. П. Сковородникова гипержанр определяется как «устойчивая речевая форма, используемая в типичных коммуникативных ситуациях, включающая в себя несколько жанров». В качестве типичного примера гипержанра в словаре-справочнике приводится практическое занятие в вузе. В этот гипержанр могут входить такие речевые жанры, как сообщение или доклад, вопросы и ответы, дискуссия, деловая игра и т. д. [3].

По мнению ученых, нужно учитывать, что у гипержанр может иметь разновидности. В частности, Е. И. Калинина отмечает, что дневник как гипержанр включает в себя несколько разновидностей, среди которых мы выделяем четыре основных: личный дневник в классическом понимании, личный дневник человека, предназначенный для публикации, дневник как форма организации литературного произведения и сетевой дневник, или блог [4].

Таким образом, понятие гипержанра соотносится с типовой ситуацией общения, с множественностью компонентов, целенаправленно объединенных в общей корпусной жанровой модели, и возможными инвариантами этой модели на разных коммуникационных носителях.

Т. В. Шмелёва считает, что для характеристики модели речевого жанра важны семь конститутивных признаков [5, с. 88-98]. Эти же признаки, по нашему мнению, могут быть положены в основание описания гипержанра. При этом основным жанроопределяющим признаком будет коммуникативная цель, которая признаётся главным фактором организации любого текста. Стоит заметить также, что гипержанр это всегда вторичное образование (в терминологии М. М. Бахтина), чаще включающее в себя диалогичные речевые жанры или их базовые характеристики [6].

С учетом высказанных теоретических положений мы можем рассмотреть эмпирический материал - отобранные для анализа видеоинтервью в новых медиа с целью аналитического описания основных жанроопределяющих признаков данного гипержанрового образования.

Прежде всего необходимо охарактеризовать контекстные признаки выбранной модели. А. В. Щербаков справедливо отмечает, что наиболее ярким проявлением смешения жанров являются публикации в интернете, когда исходный (базовый) текст не только содержит вкрапления элементов других жанров, но и сопровождается комментариями читателей, экспертов, содержит ссылки на другие тексты и т. п. [7]. Вслед за ним, исследуя такой формат публикаций в интернете, как видео- 
интервью, мы отмечаем, что, действительно, данное жанровое образование на контекстном, композиционном уровне объединяет несколько сопутствующих и взаимодействующих жанров внутри одного медиапродукта.

Основной платформой размещения видеоинтервью на сегодняшний день выступает YouTube, а для популяризации используются все существующие социальные сети (ВКонтакте, Фейсбук, Инстаграм, Одноклассники и прочие). Эмпирическим материалом нашего исследования является медийный контент более ста видеоинтервью в новых медиа, не дублирующих телевизионный контент. Среди действующих каналов их размещения - «ВДудь», «А поговорить?», «ещёнепознер», «Осторожно, Собчак!», «Не принято обсуждать», «Вписка», «Интервью с комиком», «Тһе Люди», «Зе Интервьюер», «GAZLIVE» и другие. Среди каналов, активно действовавших год назад, но изменивших формат или вовсе прекративших существование, - «Нежный редактор», «ОМ Олега Меньшикова», «Говорящие головы», «Лучшие в своем деле», «Пекло».

Чтобы привлечь и удержать внимание современного активного интернетпользователя, недостаточно одной вопросно-ответной формы беседы, на которой строится традиционное интервью, недостаточно выбрать проблемную тему для разговора - нужно, чтобы зритель в новых условиях медиадискурса, обостряющего достоверность и правдивость содержания информации (диктума), мог «прожить» информационный диалог в реальном времени, увидеть «факты» своими глазами. Как следствие, ключевые моменты беседы должны быть соотнесены с документальными кадрами. А при их отсутствии применяются различные технологии, чтобы проиллюстрировать сказанное, добиться предельной фактологичности. Так, когда хроника не успела зафиксировать реальный факт, журналисту приходится создавать «дополненную реальность» при помощи «докудрамы», ЗД-графики, театрализованной или даже танцевальной постановки. Эти сопутствующие приемы позволяют значительно расширить границы традиционного содержательного плана (диктума) интервью.

Большой объем эмпирического материала, собранного нами на YouTube, позволяет говорить, что видеоинтервью в новых медиа выходит за рамки информационных жанров, поскольку его коммуникативная цель не ограничивается передачей информации. По сути, данный гипержанр выступает одновременно и как информационный, аналитический, и как художественно-публицистический. Кроме того, такая сфера коммуникации, как интернет, позволяет не придерживаться строгого стилевого формата, которому подчинены печатные или телевизионные СМИ, что позволяет интервьюеру в новых медиа расширять содержательное поле жанра интервью и выходить за рамки сугубо публичного дискурса беседы, дополняя его новыми стилевыми фрагментами бытового дискурса: домашней хроникой или даже «неэстетичными» кадрами записи с камер видеонаблюдения.

Жанровая неоднородность ранее отмечалась нами как одна из важнейших тенденций развития видеоинтервью в новых медиа [8, с. 125-128]. Опыт наблюдения доказывает, что рассматриваемый гипержанр может совмещать в своей сложной структуре множество информационных, аналитических и художественнопублицистических микрожанровых фрагментов, умело маркируя их в общем пространстве гипержанра.

Остановимся подробнее на тех жанровых микромоделях, сложную комбинацию которых и составляет современное видеоинтервью в новых медиа.

1. Информационное интервью - диалог журналиста со вторым лицом, имеющий целью освещение факта, события, явления, рассказ о самом субъекте [9]. «Информационный фрагмент» - обязательное «содержательное ядро» в анализируемых 
видеоинтервью, что оправдано часто самим «заголовочным» маркером: практически каждое видеоинтервью основано на эксклюзивной, ранее неизвестной фактологической фабуле.

2. Аналитическое интервью - «поиск истины» в диалоге между журналистом и вторым лицом, в ходе которого журналист ограничивает себя постановкой четких вопросов, но ставит их так, чтобы ответы интервьюируемого, складываясь в логическое повествование, как можно глубже раскрыли суть выбранной темы [Там же]. «Аналитическая фактура» - неизменное условие существования и эффективного продвижения жанра видеоинтервью. Аналитическое авторское мнение и особая оценка действительности и делает этот жанр востребованным и популярным.

Информационное или аналитическое интервью выступает «стержневой жанровой моделью» в составе рассматриваемого нами гипержанра. В зависимости от задач, которые хотят решить авторы медиапродукта, на этот «стержневый жанровый фрагмент» «нанизывается» несколько других узнаваемых жанровых моделей.

3. Комментарий - объяснение, расшифровка сложной содержательно-фактуальной информации или объяснение отношения автора к данной проблеме [Там же].

Комментарий в рамках видеоинтервью может звучать из уст респондента, интервьюера или стороннего лица, компетентного в данном вопросе. Часто комментарий дается в виде титров, которые могут дополнительно озвучиваться или оставаться на экране определенное время, чтобы зритель прочел их самостоятельно. Комментарий в виде текстового фрагмента на экране позволяет зрителю видеоинтервью нажать на паузу и осмыслить новую информацию, не прибегая к помощи дополнительных источников информации.

Внутри такого медиапродукта, как видеоинтервью, комментарий может нести различные функции, среди которых мы выделяем наиболее распространенные: выражение редакцией альтернативного мнения, несогласие с позицией респондента по тому или иному вопросу; подробное раскрытие фактов по теме; расшифровка терминов, названий, аббревиатур, которые с большой долей вероятности неизвестны широкой аудитории; представление сложной для понимания информации в наглядном виде или в популярной форме.

4. Беседа - жанр, принципиальное отличие которого от интервью состоит в особой коммуникативной роли журналиста. Но следует признать, что журналист, участвующий в беседе, приобретая партию «коммуникативного лидера», должен быть неплохим специалистом в выбранной для беседы предметной области [Там же]. Беседа предполагает свободный обмен мнениями, ее формат менее регламентирован, чем интервью.

5. Опрос - представление коллективного мнения по одной или нескольким специально выбранным проблемным темам, своеобразный симбиоз жанра социологического и журналистского исследования [Там же]. Интервьюер или респондент могут задавать зрителям интересующие вопросы, на которые те пишут ответы в комментариях к видеоролику. Результаты опроса могут быть озвучены в новом выпуске или оформлены в виде самостоятельной публикации. Отметим, что опрос как «полевой сбор» информации может предварять интервью, в этом случае его результаты выступают как «подводки» к вопросам интервьюера.

6. Вопрос-ответ - ответ специалиста или редакции на вопросы читателей или зрителей (например, «прямая связь») [Там же]. Одна из форм подачи видеоинтервью в новых медиа предполагает систему, в которой зрители, наряду с вопросами интервьюера, задают вопросы непосредственно гостю в студии. Подобная жанровая форма 
максимально обеспечивает доверие зрителя автору и создателям программы, позволяет зрителю почувствовать себя в роли «соавтора» интервью.

7. Журналистское расследование - рассказ о поиске ответов на актуальные вопросы, разбор скандальных событий, криминальных историй, когда журналист собирает и анализирует факты автономно от соответствующих служб и органов или вкупе с другими специалистами [Там же].

Подобная жанровая форма, включенная в гипержанр видеоинтервью, обеспечивает ему «детективную коллизию» и «содержательную интригу», повышая рейтинг программы.

8. Документальное кино (неигровое кино) - фильм, в основу которого положены фото- и видеосъёмки подлинных событий или персон, в них участвующих. Видеоинтервью в новых медиа не ограничено жестким хронометражем, в отличие от телевизионного, поэтому позволяет привлекать дополнительные видеоматериалы в том объеме, который посчитает нужным автор медиапродукта.

Подобное «включение» документального видео обеспечивает не только фактологичность и «жизненность» рассматриваемых в видеоинтервью проблем, но и усиливает «эффект правды» в проблемном диалоге, формирует необходимую для подобного жанра контекстную средовую «рамку».

1. Исповедь - своеобразный «крик души», что характеризуется откровенностью, обнажением внутренних переживаний [Там же]. Исповедальный микрожанровый фрагмент выступает неотъемлемой частью большинства видеоинтервью в новых медиа. Происходит это по причине «установки» на интимизацию публичной сферы как таковой, а отчасти - вследствие конкурентной борьбы за большее количество просмотров.

Подобное включение прежде всего объясняет излюбленный прием публицистики, основанный на естественном желании читателя и зрителя узнать о публичной персоне нечто такое, о чем знают только «близкие люди» и чего не было ни в одном из предыдущих интервью. Вот почему интервьюер обращается ко всем возможным способам, чтобы придать общению исповедальный и предельно откровенный характер.

2. Инфографика - конвергентный жанровый прием, который представляет сочетание текста и графики и используется с намерением передать дополнительный смысл при общей поликодовости информационного потока. Кроме прямой иллюстративности, инфографические элементы: графики, схемы, таблицы, карты, диаграммы - значительно облегчают восприятие важной фактологической информации и активно «продвигают» авторское «смысловое намерение» [10].

3. Игра - один из активных жанровых приемов привлечения внимания зрителей в новом видеоинтервью. Игровые условия, как известно, всегда предполагают одного или нескольких победителей, призовые дивиденды. Активные участники просмотра получают подарки за правильные ответы на вопросы или за лучшие комментарии по теме [9].

Игровые вставки или переключения позволяют внести в видеоинтервью элемент интерактивности, привлечь ранее «невключенного», незаинтересованного зрителя к беседе. Это часто обеспечивает высокую рейтинговую популярность каналу.

Выбор жанровых элементов (своеобразных «жанровых кирпичиков») для включения в гипержанр видеоинтервью в новых медиа во многом зависит от того, на какую целевую аудиторию рассчитан медиапродукт, в каком дискурсивном поле в дальнейшем он будет востребован. 
Коммуникативная цель, согласно модели, предложенной Т. В. Шмелевой [5], один из наиболее значимых конститутивных признаков жанра. Особенностью видеоинтервью в новых медиа как гипержанра выступает сложная комбинация коммуникативных целей, которые не всегда экстравертируемы, но опознаваемы в диалоге с достаточно подготовленным, медиаграмотным зрителем. Проанализировав около сотни актуальных медиапродуктов, которые позиционируются как видеоинтервью в новых медиа, мы можем выделить часто используемые коммуникативные цели:

1. Привлечь внимание к проблеме. Примеры: «Бьет - значит бьет» (проблема домашнего насилия и принятия закона о домашнем насилии); «Беслан. Помни» на канале «ВДудь» (В проанализированных видеоинтервью содержание «организуют» следующие проблемы: недостаток информации о расследовании причин трагедии, сложности с государственной поддержкой жертв теракта, необходимость сбора средств на лечение и реабилитацию пострадавших).

2. Популяризировать и объяснить актуальные («топовые») публичные темы. Примеры: «Батыгин - русская звезда мировой науки» (интервью с астрономом) и «Гуриев - пенсионная реформа, демедведизация, доллар» (интервью с экономистом) на канале «ВДудь»; «Екатерина Шульман: выбирает преемника Путина и обижает всех» (интервью с политологом) и «Илья Новиков: Двинятин, Путин и хреновый прогноз» (интервью с адвокатом, юристом) на канале «ещенепознер». В проанализированных видеоинтервью ведущий прием - беседа и опрос, что обеспечивает диапазон мнений, широту осмысления проблемы.

3. Позиционировать «звезду». Примеры: «Нагиев - пенсии, стих в Кремле» и «Познер - о цензуре, страхе и Путине» на канале «ВДудь»,«Константин Хабенский о смелости: занять пост Табакова, защитить Голунова, спасать больных» и «Чулпан Хаматова: как спасти детей и не оказаться для всех плохой» на канале «А поговорить», «БОРТИЧ | Про работу официанткой, секс ради роли и BadComedian» на канале «Нежный редактор», «Я - явление, которое называется Хакамада» на канале «Не принято обсуждать». В проанализированных видеоинтервью ведущий представляет личность известной персоны максимально глубоко, по-новому, с неожиданной стороны, что позволяет не только решить вопросы «продвижения» имиджа той или иной «звезды», но и сформировать объективное, грамотное, а не «гламурное» информационное поле вокруг известной медийной личности.

4. «Реконструировать» событие - представить определенное историко-культурное событие, значимое для социума и сегодня, через восприятие одного или нескольких респондентов-участников события. Примеры: «Русский Вудсток. Первый рок-фест в СССР» или «MTV - главный канал нашего детства» на канале «ВДудь», «30 лет без Берлинской стены» на канале «А поговорить». В проанализированных видеоинтервью «реконструкцию» удается грамотно реализовать благодаря достоверным документальным фактам, сохранившимся в памяти «эмоциям настоящего», которые как нельзя лучше воссоздают атмосферу «события».

Следует отметить такую важную особенность современного видеоинтервью, как поликодовый медийный инструментарий, что помогает имплицитному проявлению смыслов. Здесь значимую роль приобретают невербальные медийные знаки: коммуникативные знаки поведения участников (жесты, мимика, смех, направление взгляда; поза говорящего, его одежда, прическа, макияж); общая тональность интервью-беседы (темп говорения, интонация и громкость речи, паузы в определенных местах); манипуляции с предметами в кадре и деталями габитарного имиджа (действия 
со стулом или креслом в сценическом пространстве, «игры» с ручкой, очками, сотовым телефоном.

Нельзя не сказать, что успешность жанра видеоинтервью во многом определяется числом и качеством речевых событий, спровоцированных данным медиапродуктом. Как «эхо», данный медийный дискурс «отражается», «отзывается» в последующих выдержках из него при обсуждении на форумах и в социальных сетях, в газетном или журнальном цитировании, при обсуждении в последующих теле- и радиопередачах. Нам кажется, что этот, «после» видеоинтервью возникший «информационный след» заслуживает специального, внимательного изучения.

Смешение диалогических и монологических жанровых фрагментов; комбинация информационных, аналитических и художественно-публицистических жанровых моделей, «расслоение» смысловых задач при реализации авторского намерения - все это максимально обогащает медиаинструментарий современного видеоинтервью в новых медиа и делает его таким востребованным и широко обсуждаемым.

\section{Ссылки / References}

1. Седов К. Ф. Психолингвистический аспект изучения речевых жанров // Антология речевых жанров: повседневная коммуникация / под общ. ред. К. Ф. Седова. М.: Лабиринт, 2007. C. $124-136$.

2. Дементьев В. В. Теория речевых жанров. М.: Знак, 2010. 600 с.

3. Щербаков А. В. Гипержанр // Эффективное речевое общение (базовые компетенции): словарь-справочник / Под редакцией А. П. Сковородникова. Красноярск: СФУ, 2014. C. 97-98.

4. Калинина Е. И. Системно-структурное моделирование внутрижанрового пространства гипержанра «дневник» (на материале британской лингвокультуры): Автореф. .... канд. филолог. наук. Кемерово, 2013. 24 с.

5. Шмелева Т. В. Модель речевого жанра // Жанры речи: сб. науч. статей / под ред. В. Е. Гольдина. Саратов: ГосУНЦ «Колледж», 1997. Вып. 1. С. 88-98.

6. Бахтин М. М. Проблема речевых жанров // Бахтин М. М. Собрание сочинений. Т. 5: Работы 1940-х-начала 1960-х годов. М.: 1996. С. 159-206.

7. Щербаков А. В. Жанры публицистики // Эффективное речевое общение (базовые компетенции): словарь-справочник / Под редакцией А. П. Сковородникова. Красноярск: СФУ. 2014. С. 155-156.

8. Махалова А. И. Тенденции развития видеоинтервью в новых медиа // Язык. Коммуникация. Культура - 2019 : альманах по итогам III Международной научнопрактической конференции молодых ученых - маги-странтов и аспирантов - «Язык. Коммуникация. Культура» (20 апреля 2019 г.). М.: Гос. ИРЯ им. А. С. Пушкина, 2019. C. 125-128.

9. Кобяков А. А. Расширенная классификация газетных жанров // Неофициальный сайт журфака КГУ: сайт. URL: https://kgu-

journalist.ucoz.ru/publ/zhanry_zhurnalistiki/o_zhanrakh_sovremennoj_gazetnoj_zhurnalistiki _andrej_kobjakov/6-1-0-59 (дата обращения: 15.01.2020).

10. Юфкина С. Б. Инфографика как конвергентный жанр в современных СМИ // Огарёвonline: электронное периодическое издание для студентов и аспирантов. 2015. № 19. URL: http://journal.mrsu.ru/arts/infografika-kak-konvergentnyj-zhanr-v-sovremennyx-smi (дата обращения: 15.01.2020). 